\title{
Comparação do método de parcelas com o "levantamento rápido" para amostragem da vegetação arbórea do Cerrado sentido restrito
}

\author{
Bruno Machado Teles Walter ${ }^{1,3}$ e Ernestino de Souza Gomes Guarino ${ }^{2}$
}

Recebido em 28/12/2004. Aceito em 1/09/2005

\begin{abstract}
RESUMO - (Comparação do método de parcelas com o "levantamento rápido" para amostragem da vegetação arbórea do Cerrado sentido restrito). Desde os anos 1960 o Cerrado sofre uma perda agressiva de área pelas atividades antrópicas. Visando acumular informações botânicas de forma ágil, projetos nesta região adotaram um método de amostragem expedita da vegetação, denominado "levantamento rápido" (LR). O objetivo deste estudo foi comparar e analisar a aplicação do LR com um método de parcelas, muito utilizado neste bioma. O trabalho foi realizado em um trecho de Cerrado sentido restrito na Fazenda Água Limpa, DF, Brasil (1556’S 47 $46^{\prime} \mathrm{W}$ ). Para o LR foram aplicadas três linhas de caminhada (L1, L2 e L3), registrando-se em intervalos de cinco minutos a presença das espécies inéditas que fossem encontradas. Isto permitiu a construção de uma curva espécies $\times$ tempo. Para possibilitar uma comparação direta, L1 foi coberta com 11 parcelas amostrais de $20 \times 50 \mathrm{~m}$, alocadas sobre um trecho estruturalmente homogêneo, amostrando-se todos os indivíduos com diâmetro a $30 \mathrm{~cm}$ de altura do solo $\geq 5 \mathrm{~cm}$. Quarenta minutos foi o tempo máximo para estabilizar uma curva espéciextempo individual (L2). Pelo LR foram identificadas 67 espécies, 53 gêneros e 32 famílias, enquanto nas parcelas foram identificadas 58 espécies, 45 gêneros e 27 famílias, distribuídas entre os 1.132 indivíduos amostrados. O tempo necessário para concluir a amostragem por parcelas foi de 8 horas e 17 minutos, enquanto o método rápido encerrou-se em 110 minutos. Comparando apenas L1 (concluída em 35 minutos) com parcelas, os resultados florísticos revelaram diferenças, que são analisadas à luz das características de cada método. O LR requisita técnicos com ampla experiência de campo, tendo se mostrado eficiente para registrar a riqueza do trecho estudado, com mais rapidez que as parcelas. Entretanto, LR não fornece informações estruturais da vegetação e suas sugestões de abundância são meramente especulativas. Porém, pela velocidade e facilidade de aplicação, pelo custo baixo, e pelo esforço mínimo de campo, o LR deve ser considerado como uma valiosa ferramenta para auxiliar na conservação do Cerrado.
\end{abstract}

Palavras-chave: levantamento rápido, parcelas, fitossociologia, árvores, Cerrado

\begin{abstract}
Comparison of the plot method with "rapid survey" for sampling the arboreal vegetation of Cerrado stricto sensu). The Cerrado biome has lost much of its area through human activity, and its degradation has been increasing since the 1960s. With the aim of gathering botanical information as efficiently as possible, research projects in the region have been using a fast sampling method called the rapid survey, but these methods are still the target of much academic criticism. Our aim was to compare the rapid survey with the plot method most commonly used in Central Brazil. The study was carried out in a section of Cerrado s. str. vegetation in the Federal District, Brazil, using the rapid survey along three lines (L1, L2 and L3). Walking along each line, the presence of previously unrecorded species was noted at 5-minute intervals to produce a species $\times$ time curve. L1 was divided into sample plots (11 plots of 20×50 m, surveying trees with stem diameter over $5 \mathrm{~cm}$ at $0.3 \mathrm{~m}$ above soil level), allowing for a direct comparison. Forty minutes was the longest time necessary to flatten a species $\times$ time curve (L2), and the sum of the three lines totaled 67 species, 53 genera and 32 families. In the plots 1,132 individuals were sampled over 8 hours and 17 minutes, belonging to 58 species, 45 genera and 27 families. Although exactly the same structurally homogeneous area was sampled, the floristic results from L1 and from the plots revealed differences that were analyzed in the light of the characteristics of each method. The rapid survey, which calls for participants with broad field identification experience, was a reliable way of determining the richness of the Cerrado area studied, and was more efficient than the plot method. However, it does not supply structural information about the vegetation, and the information on relative species abundance appears to be precarious, based on subjective estimates. Nevertheless, because of speed and ease of application plus low cost and minimum time spent in the field, the rapid survey should be seriously considered when urgent surveys of large areas are required. It is a valuable support tool for Cerrado conservation.
\end{abstract}

Key words: rapid survey, plots, phytosociology, trees, Cerrado

\section{Introdução}

O bioma Cerrado e, em particular, os trechos de Cerrado stricto sensu (Ribeiro \& Walter 1998) vêm sofrendo uma agressiva perda de área para as atividades humanas, cuja degradação foi muito ampliada a partir das décadas de 1960 e 1970. Ainda visto como a principal fronteira agrícola do país, a

\footnotetext{
1 Embrapa Recursos Genéticos e Biotecnologia, Parque Estação Biológica, Av. W5 Norte (final), C. Postal 02372, CEP 70770-900, Brasília, DF, Brasil

2 Laboratório de Ecologia e Conservação, Embrapa Recursos Genéticos e Biotecnologia, Brasília, DF, Brasil (esguarino@ gmail.com)

3 Autor para correspondência: bwalter@cenargen.embrapa.br
} 
abertura de áreas para atividades agropecuárias, visando à implantação de pastagens e monoculturas como a soja, juntamente com a ampliação dos pólos urbanos, construção de estradas e implantação de empreendimentos hidrelétricos, têm resultado na eliminação de áreas significativas antes cobertas por vegetação nativa (Klink et al. 1993; Ratter et al. 1997; MMA 1999; Klink \& Machado 2005).

O Cerrado é um dos 25 "hotspots" mundiais de biodiversidade, em função de sua riqueza biótica, nível de endemismos e grau de ameaça (Mittermeier et al. 1999; Myers et al. 2000). Porém, somente a partir da década de 1980 que seus aspectos florísticos e ecológicos passaram a ser alvo de investigação científica sistemática. Tanto para as áreas ocupadas por savanas quanto nos trechos de florestas, surgiram sínteses do conhecimento, como as de Goodland \& Ferri (1979), Pinto (1990), Sano \& Almeida (1998), Ribeiro et al. (2001) e Oliveira \& Marquis (2002).

$\mathrm{Na}$ área de ocupação do bioma, projetos multidisciplinares e multi-institucionais, de longo prazo, vêm realizando levantamentos em diferentes locais e fitofisionomias. Felfili et al. (1992; 1994; 2001; 2004) e Felfili \& Silva Júnior (1993; 2001), por exemplo, já levantaram trechos de Matas de Galeria, Cerradão e Cerrado stricto sensu em quinze, localizadas em três Chapadas do Brasil Central (Pratinha, dos Veadeiros e do Espigão mestre do São Francisco). No Cerrado stricto sensu, instalaram em cada área 10 parcelas de $20 \times 50$ metros, amostrando todos os indivíduos lenhosos encontrados com diâmetro de caule maior ou igual a $5 \mathrm{~cm}$, medido a $30 \mathrm{~cm}$ do solo $\left(\mathrm{DA}_{30}\right)$. Já Ratter et al. $(1996 ; 2000 ; 2001 ; 2002 ; 2003)$ vêm realizando levantamentos vegetacionais em cada unidade de $1^{\circ}$ por $1^{\circ}$ e $30^{\prime}$ de latitude e longitude, respectivamente, na área de distribuição do bioma. Para tal foi adaptado e adotado um método de levantamento rápido (LR), cuja aplicação incrementou muito o número de áreas levantadas, passíveis de serem comparadas. Estas já alcançam 376 áreas, das quais 173 foram amostradas pelo LR (Ratter et al. 2002; 2003). O método registra a riqueza florística dos locais amostrados, com base na presença e ausência de espécies, fazendo considerações sobre a abundância das mesmas.

Métodos de inventários rápidos da biota surgiram, e vêm sendo cada vez mais adotados, em função da alta velocidade da degradação ambiental e da necessidade de se dispor de uma base de dados mínima, confiável, que seja obtida de forma célere, na qual as tomadas de decisão em biologia da conservação possam se apoiar (Filgueiras 1994; Droege et al. 1998;
Alverson et al. 2000; Fonseca 2001). Discorrendo sobre o Programa de Avaliação Biológica Rápida (RAP) da Conservation International, Fonseca (2001) indicou que os sítios-alvo para execução das expedições RAP são encontrados em áreas de fronteira para o desenvolvimento, cuja descrição deve ser urgente para antecipar possíveis danos à sua integridade biológica. Segundo o autor, o objetivo é o de rapidamente coletar, analisar e disseminar informações sobre áreas pouco conhecidas, que são potencialmente importantes sob o ponto de vista da conservação da biodiversidade.

Os métodos rápidos nos trópicos têm sido adotados mais nos levantamentos de fauna (Heyer et al. 1994; Wilson et al. 1996; Emmons 1997; Droege et al. 1998) do que nos de flora (Foster et al. 2000; Ratter et al. 2000; 2001). Mas, com freqüência, ambos ainda são alvo de crítica acadêmica, uma vez que não se submetem aos rigores estatísticos. No caso da vegetação, o embasamento estatístico está presente nos tradicionais métodos de levantamentos por parcelas, cuja unidade amostral possui área fixa, ou nos métodos de distâncias ou quadrantes, cuja área é variável. Enquanto esses métodos são rotineiramente utilizados, aceitos e são bem discutidos na literatura (Cottam \& Curtis 1956; Cain \& Castro 1971; MüellerDombois \& Ellenberg 1974; Gibbs et al. 1980; Matteucci \& Colma 1982; Dias et al. 1989; Brower et al. 1990; Korning et al. 1991; Martins 1991; Alder \& Synnott 1992; Reis \& Assunção 1998; Oliveira 2000), é extremamente fragmentário o conhecimento e a discussão teórica sobre os métodos rápidos no país, seus objetivos e alcance.

O presente trabalho objetivou contribuir nesta discussão, ao comparar a aplicação do LR adaptado por Ratter et al. (2000; 2001), com um dos métodos de parcela mais utilizados no Cerrado sentido restrito do Brasil Central, adotado por Felfili et al. (1994; 2001; 2004). As vantagens, limitações e o tempo necessário para amostrar a vegetação por cada método foram analisados, com base em um trecho de Cerrado sentido restrito no Distrito Federal (DF).

\section{Material e métodos}

Local de estudo - O estudo foi realizado na Fazenda Água Limpa (FAL), localizada na Área de Proteção Ambiental (APA) das bacias do Gama e Cabeça de Veado. Esta APA localiza-se ao sul da cidade de Brasília, abarcando cerca de 25.000 ha. Trata-se de uma das mais importantes unidades de conservação 
do DF, englobando áreas no Jardim Botânico de Brasília (JBB), na Reserva Ecológica do Instituto Brasileiro de Geografia e Estatística (IBGE) e na FAL.

Parte relevante da APA, a Fazenda Água Limpa é uma fazenda experimental pertencente à Universidade de Brasília e contempla uma reserva ecológica. Situa-se ao sul de Brasília (1556’S e $47^{\circ} 46^{\prime} \mathrm{W}$ ), em altitude média de $1.100 \mathrm{~m}$. Possui aproximadamente 4.000 ha de área, onde há o predomínio de Latossolos distróficos sob seu principal tipo de vegetação, o Cerrado sentido restrito (Ratter 1980; 1991; Felfili \& Silva Júnior 1992). O clima da região é do tipo Aw de Köppen. A FAL foi escolhida como área de estudo pelo fato de ser floristicamente bem conhecida, o que permitiu comparação direta com estudos anteriores desenvolvidos na área (Felfili \& Silva Júnior 1988; 1992; Ratter 1980; 1991).

Levantamento rápido: teoria - O LR é um método de amostragem que visa coletar dados qualitativos de forma expedita, cujos princípios são similares ao método do "caminhamento" descrito por Filgueiras et al. (1994). Segundo Ratter et al. (2000; 2001; 2003), o método está baseado em levantamentos designados "wide patrolling" ("varredura"). Basicamente, o LR consiste da realização de pelo menos três caminhadas em linha reta na vegetação, anotando-se durante intervalos de tempo regulares (intervalos que podem variar de cinco a 15 minutos - o que se define em função do tipo de vegetação e do detalhamento pretendido), consecutivos, as espécies inéditas que vão sendo visualizadas. Para o Cerrado sentido amplo (lato sensu), Ratter et al. (2001) utilizaram intervalos de 15 minutos e caminhadas com três participantes, posicionados a $20 \mathrm{~m}$ uns dos outros. Isto permite cobrir visualmente uma faixa com cerca de $60 \mathrm{~m}$ de largura, supondo que cada pessoa visualize cerca de $10 \mathrm{~m}$ para cada lado de sua linha de caminhada, ou $20 \mathrm{~m}$ no total.

O LR assemelha-se ao caminhamento de Filgueiras et al. (1994) nos seguintes aspectos: 1) considera os diferentes tipos de vegetação presentes na área a ser amostrada; 2) recomenda que as caminhadas procurem ser retas; 3) preocupa-se com a representatividade florística da amostra (enquanto no caminhamento recomenda-se que sejam feitas tantas caminhadas até que não sejam mais encontradas novas espécies, no LR almeja-se a estabilização de uma curva espécies $\times$ tempo); 4) sugere que se façam estimativas da abundância das espécies na área, sob as categorias "abundante", "freqüente", "comum", "ocasional” e "rara"; e 5) preconiza coletas de material testemunho para herbário. Difere do caminhamento por considerar a variável tempo, assim como preocupa-se em estratificar a vegetação amostrada (em camada lenhosa e herbácea, ou estrato arbóreo-arbustivo e herbáceo).

Quanto à estratificação, Ratter et al. (2000; 2001; 2003) procuraram registrar somente árvores e arbustos grandes da camada lenhosa do Cerrado sentido amplo. Em situações práticas, J.A. Ratter (com. pes.) informou que as plantas com diâmetro na base maiores que $3 \mathrm{~cm}$ e altura total superior a $1,5 \mathrm{~m}$ seriam as visadas, embora indivíduos jovens de espécies cujos adultos alcancem o estrato arbóreo também sejam considerados. Entretanto, nenhuma medida a esse respeito é tomada em campo. Além dessas diferenças, enquanto Filgueiras et al. (1994) recomendaram a coleta de material botânico de todas as plantas que se encontrassem com flores ou frutos, Ratter et al. (2000; 2001; 2003) sugeriram somente a coleta das espécies desconhecidas, ou de identificação duvidosa.

Levantamento rápido: prática - O LR foi aplicado em três linhas de caminhada, denominadas "Linha 1" (L1), "Linha 2" (L2) e "Linha 3" (L3), anotando-se, a intervalos de cinco minutos, a presença das espécies inéditas que fossem encontradas. O intervalo de cinco minutos, inferior aos 15 minutos adotados por Ratter et al. (2001; 2003), visou detalhar os dados da construção da curva espécies $\times$ tempo. O registro da presença das espécies a cada intervalo foi diferenciado por meio de símbolos anotados em frente aos nomes das mesmas, em uma lista das espécies arbóreas do Cerrado da FAL, previamente preparada com base na listagem de Ratter (1991). Símbolos diferentes registraram diferentes intervalos de cinco minutos, para cada uma das linhas de caminhada (L1, L2 e L3).

As três linhas de caminhada ficaram distanciadas em cerca de $500 \mathrm{~m}$ entre si. Somente L1 foi coberta com parcelas amostrais, mas o foi por inteiro, o que permitiu a comparação direta dos resultados obtidos para cada método. Nesse sentido, a faixa de visualização da caminhada na L1 cobriu $20 \mathrm{~m}$, arbitrando-se em até 10 m o campo de visão para cada lado da linha de caminhada. Na prática, em torno de $5 \mathrm{~m}$ para cada lado da linha de caminhada é que permite uma visualização acurada. Esses limites não são obrigatórios, nem mesmo são considerados formalmente pelo método, que relata distâncias entre os participantes de 10 a 20 m (Ratter et al. 2001), mas no presente estudo procuraram ser rígidas para delimitar o trecho de observação, visando a comparação equânime com as parcelas alocadas na L1. 
Objetivando englobar uma porção da vegetação estruturalmente homogênea (Cerrado Típico, sensu Ribeiro \& Walter 1998), L1 foi subdividida em três trechos (T1, T2 e T3), distanciados em 100 m cada (Fig. 1). Isto facilitou a posterior alocação das parcelas, que incluíram a linha de caminhada, e seu campo de visão, exatamente na posição central (Fig. 1). Enquanto em situações práticas as caminhadas de LR não são retas perfeitas (e não há necessidade de que sejam), nos segmentos da L1 elas o foram. A segmentação dessa linha nos três trechos também teve esse objetivo.

O LR foi aplicado até o momento em que em algum dos intervalos de cinco minutos não mais fossem observadas espécies inéditas. Esse critério também foi adotado para L2 e L3 que, diferentemente de L1, foram efetivamente retas contínuas.

O levantamento de L1 foi feito antes da alocação das parcelas para que não houvesse nenhum contato anterior com a porção de cerrado amostrada, evitando possíveis induções quanto à presença de espécies. Nas linhas L2 e L3, levantadas após a L1 e as parcelas, a mesma faixa de $20 \mathrm{~m}$ (10 m para cada lado da caminhada) procurou ser respeitada. Com o levantamento das linhas L2 e L3, a faixa de $60 \mathrm{~m}$ coberta por Ratter et al. (2001) foi atendida. Não foi nosso objetivo dispor de uma lista completa da flora, realizando outras linhas de caminhada. Ao contrário, buscou-se comparar diretamente os resultados qualitativos de L1 com os dados quantitativos e qualitativos obtidos pelas parcelas, considerando as informações de L2 e L3 como dados florísticos complementares.

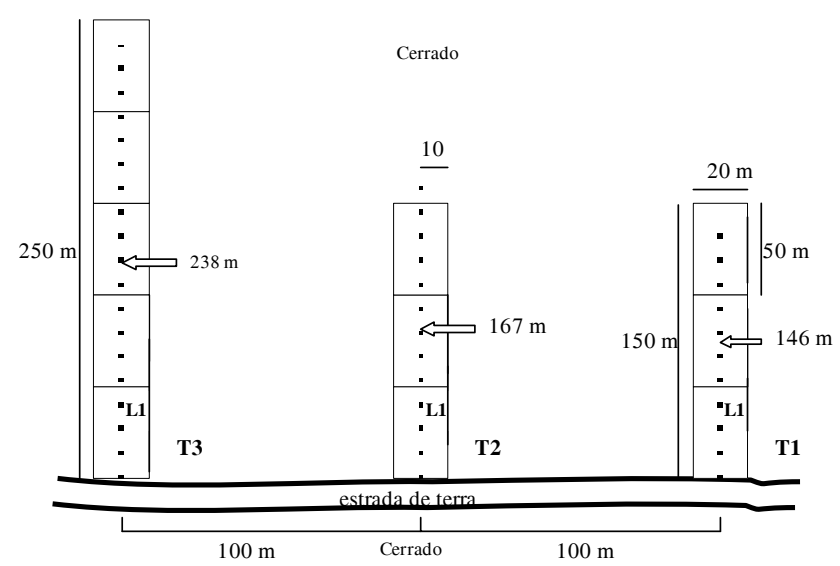

Figura 1. Esquema de alocação das parcelas (11 parcelas de $20 \times 50 \mathrm{~m}$ ) e da Linha 1 de caminhada pelo "levantamento rápido" (indicada pela linha hachurada), no Cerrado sentido restrito na Fazenda Água Limpa, DF, Brasil. A caminhada da Linha 1 iniciou-se no trecho T1 (de $146 \mathrm{~m}$ ), seguindo-se T2 (167 m) e T3 $(238 \mathrm{~m})$. Ver texto para maiores explicações.
Tentativamente, somente as plantas com $\mathrm{DA}_{30} \geq 5 \mathrm{~cm}$ deveriam ser consideradas, embora nenhuma medida nesse sentido tenha sido feita respeitando o método. Optou-se por este diâmetro para adequar-se ao método de parcelas comparado, evitando assim uma possível indicação maior de riqueza por este método, devida somente ao critério de inclusão de espécies diferenciado.

Parcelas - Os três trechos de caminhada da L1 foram circundados por parcelas de 20×50 m (Fig. 1). Nesse sentido foram necessárias 11 parcelas, totalizando 1,1 ha amostrado. Isto representa 0,1 ha a mais do que o mínimo preconizado por Felfili et al. (2001) para a amostragem no Cerrado sentido restrito. $\mathrm{Na}$ comparação de tempo gasto para cada método, essa diferença foi considerada.

Nos trechos T1 e T3 toda a linha de caminhada foi incluída pelas parcelas, as quais excederam a linha de caminhada em $4 \mathrm{~m}$ em T1, e em $12 \mathrm{~m}$ em T3 (Fig. 1). Em T2, no entanto, a linha de caminhada excedeu as parcelas em $17 \mathrm{~m}$, de modo que isto foi compensado por T1 e T3 (Fig. 1) conforme comentado.

$\mathrm{O}$ método de parcelas foi aplicado como nos trabalhos de Felfili et al. (1994; 2001; 2004) e Felfili \& Silva Júnior (2001), exceto pela preconizada aleatorização das parcelas na vegetação. Se esta fosse seguida, tornaria impossível a comparação. Assim, foram amostrados todos os indivíduos com DAP $\geq 5 \mathrm{~cm}$, anotando-se também a altura total dos indivíduos. As medidas de diâmetro foram tomadas com uma suta graduada até $50 \mathrm{~cm}$ e as alturas totais dos indivíduos estimadas visualmente (Felfili et al. 2001). Devido a sua importância no trecho estudado, palmeiras e canelas-de-ema (Vellozia) foram incluídas, visando a uma melhor indicação da estrutura da vegetação e melhor comparação florística. Os parâmetros fitossociológicos, densidade, dominância, frequiência e o Índice do Valor de Importância (Müeller-Dombois \& Ellenberg 1974), foram calculados pelo programa Inflo, desenvolvido no Departamento de Engenharia Florestal da Universidade de Brasília.

Tempo e coleta de dados - Todo o tempo gasto no campo nos procedimentos de cada método foi anotado, assim como, para o LR, foi medida a distância percorrida em metros a cada intervalo de cinco minutos. Para investigar a relação entre o tempo gasto para amostrar cada parcela e o número de indivíduos nela contido, realizou-se uma análise de correlação de Spearman $\left(r_{s}\right)$ com nível de significância $p<0,05$ (Zar 1999). 
Somente os autores participaram da coleta de dados, lembrando que, normalmente, equipes com três e até cinco integrantes participam da coleta de dados pelo método de parcelas e que Ratter et al. (2001) indicaram três participantes no LR. O material testemunho das espécies citadas neste trabalho está depositado nos Herbários UB e IBGE, mas não foram feitas novas coleções. Isso segue as recomendações de Anderson (1996), de que se evite a coleta de espécimes em uma área bem conhecida e fartamente coletada. Além disso, somente um táxon (Bauhinia sp.) não pode ser identificado ao nível de espécie, pois encontrava-se estéril durante os trabalhos de campo. As abreviaturas dos nomes dos autores dos táxons seguiram Brummitt \& Powell (1992).

\section{Resultados e discussão}

Levantamento rápido - O LR registrou a presença de 67 espécies, pertencentes a 53 gêneros e 32 famílias (Tab. 1). Pela soma de dois intervalos de 35 minutos e um de 40 das três linhas, foi necessário uma hora e cinqüenta minutos para obter essa informação (Tab. 2). No entanto, considerando que os dados obtidos nas caminhadas nesse método são analisados em conjunto (Ratter et al. 2001), e as caminhadas podem ser realizadas por mais equipes, 40 minutos seria o tempo necessário para concluir esse levantamento (Tab. 2).

Somente na L1 foram amostradas 59 espécies pertencentes a 48 gêneros e 30 famílias. Para essa informação de L1 foram gastos exatos 35 minutos, percorrendo-se $551 \mathrm{~m}$ (Tab. 2). No primeiro trecho foram percorridos $146 \mathrm{~m}$, em 15 minutos (Tab. 2). No segundo trecho foram percorridos $167 \mathrm{~m}$, em 10 minutos, e no terceiro trecho $238 \mathrm{~m}$, também em 10 minutos (Tab. 2). Com o passar do tempo foi necessário caminhar mais para encontrar alguma espécie inédita ao levantamento, sendo que o maior trecho percorrido por intervalo foi o último $(129 \mathrm{~m})$, sem resultar na observação de nenhuma espécie inédita. Este fato motivou o encerramento dessa coleta de dados na L1.

Com as L2 e 3 do LR a mesma tendência foi verificada. Foram gastos 40 minutos na L2 para encontrar 59 espécies, 46 gêneros e 29 famílias ( $831 \mathrm{~m}$ percorridos), e 35 minutos na L3, registrando 61 espécies, 47 gêneros e 31 famílias ( $825 \mathrm{~m}$ ). No primeiro intervalo de cinco minutos dessas linhas foram percorridos 55 e $58 \mathrm{~m}$, registrando-se 31 e 35 espécies, respectivamente. Em ambas, no último intervalo não foram encontradas espécies inéditas, tendo sido percorridos em L2 155 m e em L3 159 m. Quando L1,
L2 e L3 são analisadas em conjunto, 46 espécies foram registradas nos primeiros cinco minutos, as quais totalizaram 56 espécies nos primeiros 10 minutos, sendo que apenas 11 espécies foram registradas na meia hora seguinte.

As curvas espécies $\times$ tempo traçadas sugerem a tendência de estabilização, que se inicia a partir do vigésimo minuto para as três linhas, indicando que a amostragem foi suficiente (Fig. 2A). A curva geral traçada, baseada nas três linhas, como esperado foi sempre superior a cada linha individual.

Em termos de riqueza, os números encontrados para cada linha do LR ficaram muito próximos de alguns dados publicados para o Cerrado da FAL ou da APA do Gama e Cabeça de Veado, quando a comparação se dá com trabalhos de amostragem fitossociológica (Tab. 3). Nas linhas L2 e L3 o padrão da vegetação também foi de um Cerrado Típico, mas que englobou manchas de Cerrado Ralo e Denso em L2 (onde foi registrada Copaifera langsdorffii, por exemplo) e de Cerrado Ralo em L3 (subtipos fitofisionômicos no sentido de Ribeiro \& Walter 1998). Essas mudanças estruturais, que se refletiram na florística, explicam porque em L2 e L3 foram necessários mais de $820 \mathrm{~m}$ para encerrar os levantamentos, enquanto na homogênea L1 $551 \mathrm{~m}$ foram suficientes.

Ratter (1991) amostrou na FAL somente 48 espécies, mas em área correspondente a 0,475 ha, em 19 parcelas de $25 \times 10 \mathrm{~m}$ alocadas sobre um longo transecto que também englobou variações estruturais da fisionomia (Tab. 3). No criterioso trabalho de florística que realizou na Fazenda, o mesmo autor informou a presença de 109 espécies de árvores e arbustos de maior porte, pertencentes a 46 famílias, ocorrendo no Cerrado (sentido amplo). Foi essa a listagem base usada para coletar os dados pelo LR.

Com base apenas em L1, estas comparações mostram que o LR realizado, numa única caminhada em um trecho homogêneo da FAL, foi muito eficiente para indicar a riqueza daquela área. Se consideradas as três linhas do LR (32 famílias e 67 espécies), a riqueza da FAL foi superior ao indicado antes por Felfili et al. $(1992 ; 1994)$ para toda a APA, usando o método de parcelas. Segundo Ratter et al. (2001), o LR, em cerca de 60 minutos, chega a amostrar mais de $90 \%$ das espécies encontradas em cada local.

Parcelas - No levantamento por parcelas foram amostrados 1.132 indivíduos, pertencentes a 58 espécies, 45 gêneros e 27 famílias (Tab. 1, 3). Isto representa nove espécies, oito gêneros e cinco famílias 
Tabela 1. Táxons amostrados pelo levantamento rápido (LR) e parâmetros fitossociológicos referentes a uma área de 1,1 ha de Cerrado sentido restrito na Fazenda Água Limpa, DF, Brasil. N = número de indivíduos amostrados; DR = densidade relativa; DoR = dominância relativa; FR = freqüência relativa; IVI = índice do valor de importância. L1, L2 e L3 = linhas do LR. "X" = indica a presença da espécie no LR ou Parcelas.

\begin{tabular}{|c|c|c|c|c|c|c|c|c|c|}
\hline \multirow[t]{2}{*}{ Família/Espécie } & \multirow[t]{2}{*}{$\mathrm{N}$} & \multirow[t]{2}{*}{ DR } & \multirow[t]{2}{*}{ DoR } & \multirow[t]{2}{*}{ FR } & \multirow[t]{2}{*}{ IVI } & \multicolumn{3}{|c|}{ LR } & \multirow{2}{*}{$\begin{array}{l}\text { Parcelas } \\
\text { Em L1 }\end{array}$} \\
\hline & & & & & & $\mathrm{L} 1$ & $\mathrm{~L} 2$ & L3 & \\
\hline \multicolumn{10}{|l|}{ APOCYNACEAE } \\
\hline Aspidosperma macrocarpon Mart. & 8 & 0,71 & 0,90 & 1,43 & 3,04 & $\mathrm{X}$ & $\mathrm{X}$ & $\mathrm{X}$ & $\mathrm{X}$ \\
\hline A. tomentosum Mart. & 28 & 2,47 & 1,94 & 2,86 & 7,27 & $\mathrm{X}$ & $\mathrm{X}$ & $\mathrm{X}$ & $\mathrm{X}$ \\
\hline $\begin{array}{l}\text { Hancornia speciosa Gomesz var. pubescens } \\
\text { (Nees. \& Mart.) Müll. Arg. }\end{array}$ & 1 & 0,09 & 0,06 & 0,29 & 0,44 & $\mathrm{X}$ & $\mathrm{X}$ & - & $X$ \\
\hline Himatanthus obovatus (Müll. Arg.) Woodson & 2 & 0,18 & 0,09 & 0,29 & 0,55 & $\mathrm{X}$ & - & - & $\mathrm{X}$ \\
\hline \multicolumn{10}{|l|}{ ARALIACEAE } \\
\hline $\begin{array}{l}\text { Schefflera macrocarpa (Cham. \& Schltdl.) Frodin } \\
\text { BIGNONIACEAE }\end{array}$ & 65 & 5,74 & 5,63 & 3,14 & 14,52 & $\mathrm{X}$ & $\mathrm{X}$ & $\mathrm{X}$ & $\mathrm{X}$ \\
\hline \multicolumn{9}{|l|}{ BOMBACACEAE } & $\mathrm{X}$ \\
\hline \multicolumn{9}{|l|}{ CARYOCARACEAE } & $\mathrm{X}$ \\
\hline $\begin{array}{l}\text { Caryocar brasiliense Cambess. } \\
\text { CELASTRACEAE }\end{array}$ & 44 & 3,89 & 6,23 & 3,14 & 13,26 & $\mathrm{X}$ & $\mathrm{X}$ & $\mathrm{X}$ & $\mathrm{X}$ \\
\hline Plenckia populnea Reissek. & - & - & - & - & - & - & - & $\mathrm{X}$ & - \\
\hline \multicolumn{10}{|l|}{ COMPOSITAE (ASTERACEAE) } \\
\hline Eremanthus glomerulatus Less. & 46 & 4,06 & 1,87 & 2,86 & 8,79 & $\mathrm{X}$ & $\mathrm{X}$ & $\mathrm{X}$ & $\mathrm{X}$ \\
\hline Piptocarpha rotundifolia (Less.) Baker & 13 & 1,15 & 0,86 & 2,00 & 4,01 & $\mathrm{X}$ & $\mathrm{X}$ & $\mathrm{X}$ & $\mathrm{X}$ \\
\hline \multicolumn{10}{|l|}{ CONNARACEAE } \\
\hline Connarus suberosus Planch. & 3 & 0,27 & 0,16 & 0,57 & 0,99 & $\mathrm{X}$ & $\mathrm{X}$ & $\mathrm{X}$ & $\mathrm{X}$ \\
\hline Rourea induta Planch. & 11 & 0,97 & 0,46 & 1,71 & 3,15 & $\mathrm{X}$ & $\mathrm{X}$ & $\mathrm{X}$ & $\mathrm{X}$ \\
\hline \multicolumn{10}{|l|}{ DILLENIACEAE } \\
\hline Davilla elliptica A. St.-Hil. & - & - & - & - & - & $\mathrm{X}$ & $\mathrm{X}$ & $\mathrm{X}$ & - \\
\hline \multicolumn{10}{|l|}{ EBENACEAE } \\
\hline Diospyros burchellii DC. & 10 & 0,88 & 0,42 & 1,71 & 3,02 & $\mathrm{X}$ & $\mathrm{X}$ & $\mathrm{X}$ & $\mathrm{X}$ \\
\hline \multicolumn{10}{|l|}{ ERYTHROXYLACEAE } \\
\hline Erythroxylum deciduum A. St.-Hil. & 7 & 0,62 & 0,20 & 1,14 & 1,96 & $\mathrm{X}$ & $\mathrm{X}$ & $X$ & $\mathrm{X}$ \\
\hline E. suberosum A. St.-Hil. & 21 & 1,86 & 0,67 & 2,29 & 4,81 & $\mathrm{X}$ & $\mathrm{X}$ & $\mathrm{X}$ & $\mathrm{X}$ \\
\hline E. tortuosum Mart. & 5 & 0,44 & 0,26 & 1,14 & 1,84 & $\mathrm{X}$ & $\mathrm{X}$ & $\mathrm{X}$ & $\mathrm{X}$ \\
\hline \multicolumn{10}{|l|}{ FLACOURTIACEAE } \\
\hline Casearia sylvestris Sw. & - & - & - & - & - & $\mathrm{X}$ & - & - & - \\
\hline GUTTIFERAE (CLUSIACEAE) & & & & & & & & & \\
\hline Kielmeyera coriacea Mart. \& Zucc. & 38 & 3,36 & 1,67 & 2,86 & 7,89 & - & - & $\mathrm{X}$ & $\mathrm{X}$ \\
\hline K. speciosa A. St.-Hil. & 1 & 0,09 & 0,03 & 0,29 & 0,40 & $\mathrm{X}$ & $\mathrm{X}$ & $\mathrm{X}$ & $\mathrm{X}$ \\
\hline HIPPOCRATEAECEAE & & & & & & & & & \\
\hline Salacia crassifolia (Mart. ex. Schult.) G. Don. & 11 & 0,97 & 0,45 & 1,43 & 2,85 & $\mathrm{X}$ & $\mathrm{X}$ & $\mathrm{X}$ & $\mathrm{X}$ \\
\hline LEGUMINOSAE/CAESALPINOIDEAE & & & & & & & & & \\
\hline Bauhinia sp. & - & - & - & - & - & $\mathrm{X}$ & - & - & - \\
\hline Copaifera langsdorffii Desf. & - & - & - & - & - & - & $\mathrm{X}$ & - & - \\
\hline Hymenaea stigonocarpa Mart. ex. Hayne & 7 & 0,62 & 0,92 & 1,71 & 3,25 & $\mathrm{X}$ & $\mathrm{X}$ & $\mathrm{X}$ & $\mathrm{X}$ \\
\hline $\begin{array}{l}\text { Sclerolobium paniculatum Vogel var. subvelutinum } \\
\text { Benth. }\end{array}$ & 53 & 4,68 & 15,35 & 3,14 & 23,17 & $\mathrm{X}$ & $\mathrm{X}$ & $\mathrm{X}$ & $\mathrm{X}$ \\
\hline LEGUMINOSAE/MIMOSOIDEAE & & & & & & & & & \\
\hline Dimorphandra mollis Benth. & 4 & 0,35 & 0,34 & 0,86 & 1,55 & $\mathrm{X}$ & $\mathrm{X}$ & $\mathrm{X}$ & $\mathrm{X}$ \\
\hline Enterolobium gummiferum (Mart.) J.F. Macbr. & 3 & 0,27 & 0,31 & 0,86 & 1,43 & $\mathrm{X}$ & $\mathrm{X}$ & $\mathrm{X}$ & $\mathrm{X}$ \\
\hline Mimosa claussenii Benth. & 12 & 1,06 & 0,36 & 1,71 & 3,13 & $\mathrm{X}$ & $\mathrm{X}$ & $\mathrm{X}$ & $\mathrm{X}$ \\
\hline Stryphnodendron adstringens (Mart.) Coville & 43 & 3,80 & 2,95 & 2,86 & 9,61 & $\mathrm{X}$ & $\mathrm{X}$ & $\mathrm{X}$ & $\mathrm{X}$ \\
\hline LEGUMINOSAE/PAPILONOIDEAE & & & & & & & & & \\
\hline Acosmium dasycarpum (Vogel) Yakovlev & 2 & 0,18 & 0,16 & 0,57 & 0,91 & - & - & - & $\mathrm{X}$ \\
\hline Bowdichia virgiloides Kunth & 2 & 0,18 & 0,06 & 0,57 & 0,81 & $\mathrm{X}$ & $\mathrm{X}$ & - & $\mathrm{X}$ \\
\hline Dalbergia miscolobium Benth. & 18 & 1,59 & 3,41 & 2,57 & 7,57 & $\mathrm{X}$ & $\mathrm{X}$ & $\mathrm{X}$ & $\mathrm{X}$ \\
\hline
\end{tabular}


Tabela 1 (continuação)

\begin{tabular}{|c|c|c|c|c|c|c|c|c|c|}
\hline \multirow[t]{2}{*}{ Família/Espécie } & \multirow[t]{2}{*}{$\mathrm{N}$} & \multirow[t]{2}{*}{ DR } & \multirow[t]{2}{*}{ DoR } & \multirow[t]{2}{*}{ FR } & \multirow[t]{2}{*}{ IVI } & \multicolumn{3}{|c|}{ LR } & \multirow{2}{*}{$\begin{array}{c}\text { Parcelas } \\
\text { Em L1 }\end{array}$} \\
\hline & & & & & & L1 & $\mathrm{L} 2$ & L3 & \\
\hline $\begin{array}{l}\text { Pterodon pubescens (Benth.) Benth. } \\
\text { LOGANIACEAE }\end{array}$ & 6 & 0,53 & 0,52 & 1,14 & 2,20 & $\mathrm{X}$ & $\mathrm{X}$ & $\mathrm{X}$ & $\mathrm{X}$ \\
\hline Strychnos pseudoquina A. St.-Hil. & 4 & 0,35 & 0,56 & 1,14 & 2,06 & $\mathrm{X}$ & $\mathrm{X}$ & $\mathrm{X}$ & $\mathrm{X}$ \\
\hline LYTHRACEAE & & & & & & & & & \\
\hline $\begin{array}{l}\text { Lafoensia pacari A. St.-Hil. } \\
\text { MALPIGHIACEAE }\end{array}$ & 3 & 0,27 & 0,27 & 0,86 & 1,39 & - & - & $X$ & $\mathrm{X}$ \\
\hline Byrsonima coccolobifolia Kunth & 1 & 0,09 & 0,03 & 0,29 & 0,40 & $\mathrm{X}$ & $\mathrm{X}$ & $\mathrm{X}$ & $\mathrm{X}$ \\
\hline B. crassa Nied. & 43 & 3,80 & 1,91 & 2,86 & 8,56 & $\mathrm{X}$ & $\mathrm{X}$ & $\mathrm{X}$ & $X$ \\
\hline B. verbascifolia (L.) DC. & 4 & 0,35 & 0,17 & 1,14 & 1,66 & $\mathrm{X}$ & $\mathrm{X}$ & $\mathrm{X}$ & $\mathrm{X}$ \\
\hline Heteropterys byrsonimifolia A. Juss. & 3 & 0,27 & 0,11 & 0,86 & 1,23 & $\mathrm{X}$ & - & $\mathrm{X}$ & $\mathrm{X}$ \\
\hline MELASTOMATACEAE & & & & & & & & & \\
\hline Miconia albicans (Sw.) Triana & 26 & 2,30 & 1,74 & 2,57 & 6,60 & $\mathrm{X}$ & $\mathrm{X}$ & $\mathrm{X}$ & $\mathrm{X}$ \\
\hline M. ferruginata DC. & 18 & 1,59 & 1,73 & 2,86 & 6,18 & $\mathrm{X}$ & $\mathrm{X}$ & $\mathrm{X}$ & $\mathrm{X}$ \\
\hline M. pohliana Cogn. & 9 & 0,80 & 0,44 & 1,14 & 2,38 & $\mathrm{X}$ & $\mathrm{X}$ & $\mathrm{X}$ & $\mathrm{X}$ \\
\hline MORACEAE & & & & & & & & & \\
\hline Brosimum gaudichaudii Trécul. & - & - & - & - & - & $\mathrm{X}$ & $\mathrm{X}$ & $\mathrm{X}$ & - \\
\hline MYRSINACEAE & & & & & & & & & \\
\hline Myrsine guianensis (Aubl.) Kuntze & 6 & 0,53 & 0,31 & 1,43 & 2,27 & $\mathrm{X}$ & $\mathrm{X}$ & $X$ & $\mathrm{X}$ \\
\hline MYRTACEAE & & & & & & & & & \\
\hline Blepharocalyx salicifolius (Kunth) O. Berg & 16 & 1,41 & 4,45 & 2,86 & 8,72 & $\mathrm{X}$ & $\mathrm{X}$ & $\mathrm{X}$ & $\mathrm{X}$ \\
\hline Psidium laruotteanum Cambess. & 2 & 0,18 & 0,34 & 0,57 & 1,09 & $\mathrm{X}$ & - & $\mathrm{X}$ & $\mathrm{X}$ \\
\hline Siphoneugena densiflora O. Berg & 1 & 0,09 & 0,08 & 0,29 & 0,45 & $\mathrm{X}$ & $\mathrm{X}$ & $\mathrm{X}$ & $\mathrm{X}$ \\
\hline NYCTAGINACEAE & & & & & & & & & \\
\hline Guapira noxia (Netto) Lundell & 6 & 0,53 & 0,40 & 1,43 & 2,36 & $\mathrm{X}$ & $\mathrm{X}$ & $\mathrm{X}$ & $\mathrm{X}$ \\
\hline Neea theifera Oersted. & 3 & 0,27 & 0,07 & 0,86 & 1,20 & $\mathrm{X}$ & $\mathrm{X}$ & $\mathrm{X}$ & $X$ \\
\hline OCHNACEAE & & & & & & & & & \\
\hline Ouratea hexasperma (A. St.-Hil.) Baill. & 153 & 13,52 & 9,05 & 3,14 & 25,71 & $\mathrm{X}$ & $\mathrm{X}$ & $\mathrm{X}$ & $X$ \\
\hline PALMAE (ARECACEAE) & & & & & & & & & \\
\hline Butia archeri (Glassman) Glassman & 2 & 0,18 & 0,33 & 0,57 & 1,08 & $\mathrm{X}$ & $\mathrm{X}$ & $\mathrm{X}$ & $\mathrm{X}$ \\
\hline Syagrus comosa (Mart.) Mart. & 24 & 2,12 & 2,87 & 2,29 & 7,28 & $\mathrm{X}$ & $\mathrm{X}$ & $\mathrm{X}$ & $\mathrm{X}$ \\
\hline S. flexuosa (Mart.) Becc. & 22 & 1,94 & 0,99 & 2,57 & 5,50 & $\mathrm{X}$ & $\mathrm{X}$ & $\mathrm{X}$ & $X$ \\
\hline PROTEACEAE & & & & & & & & & \\
\hline Roupala montana Aubl. & 25 & 2,21 & 1,27 & 2,57 & 6,05 & $\mathrm{X}$ & $\mathrm{X}$ & $\mathrm{X}$ & $\mathrm{X}$ \\
\hline RUBIACEAE & & & & & & & & & \\
\hline Palicourea rigida Kunth & 10 & 0,88 & 0,48 & 1,71 & 3,07 & $\mathrm{X}$ & $\mathrm{X}$ & $\mathrm{X}$ & $\mathrm{X}$ \\
\hline Tocoyena formosa (Cham. \& Schldt.) K. Schum. & - & - & - & - & - & - & $\mathrm{X}$ & $\mathrm{X}$ & - \\
\hline SAPOTACEAE & & & & & & & & & \\
\hline Pouteria ramiflora (Mart.) Radlk. & 19 & 1,68 & 1,68 & 1,71 & 5,08 & $\mathrm{X}$ & $\mathrm{X}$ & $\mathrm{X}$ & $\mathrm{X}$ \\
\hline P. torta (Mart.) Radlk. & - & - & - & - & - & - & $\mathrm{X}$ & $\mathrm{X}$ & - \\
\hline STYRACACEAE & & & & & & & & & \\
\hline Styrax ferrugineus Nees. \& Mart. & 4 & 0,35 & 0,20 & 1,14 & 1,69 & $\mathrm{X}$ & $\mathrm{X}$ & $\mathrm{X}$ & $\mathrm{X}$ \\
\hline SYMPLOCACEAE & & & & & & & & & \\
\hline Symplocos rhamifolia A. DC. & - & - & - & - & - & $\mathrm{X}$ & $\mathrm{X}$ & $\mathrm{X}$ & - \\
\hline VELLOZIACEAE & & & & & & & & & \\
\hline Vellozia squamata Pohl & 42 & 3,71 & 2,44 & 3,14 & 9,30 & $\mathrm{X}$ & $\mathrm{X}$ & $\mathrm{X}$ & $X$ \\
\hline VOCHYSIACEAE & & & & & & & & & \\
\hline Qualea grandiflora Mart. & 76 & 6,71 & 8,22 & 3,14 & 18,07 & $\mathrm{X}$ & $\mathrm{X}$ & $\mathrm{X}$ & $\mathrm{X}$ \\
\hline Q. multiflora Mart. & 11 & 0,97 & 0,89 & 2,29 & 4,15 & $\mathrm{X}$ & $\mathrm{X}$ & $\mathrm{X}$ & $\mathrm{X}$ \\
\hline Q. parviflora Mart. & 87 & 7,69 & 8,53 & 3,14 & 19,36 & $\mathrm{X}$ & $\mathrm{X}$ & $\mathrm{X}$ & $\mathrm{X}$ \\
\hline Vochysia elliptica Mart. & 23 & 2,03 & 1,31 & 2,57 & 5,91 & $\mathrm{X}$ & $\mathrm{X}$ & $\mathrm{X}$ & $\mathrm{X}$ \\
\hline V. rufa Mart. & - & - & - & - & - & - & $\mathrm{X}$ & $\mathrm{X}$ & - \\
\hline V. thyrsoidea Pohl & 4 & 0,35 & 0,78 & 1,14 & 2,28 & $\mathrm{X}$ & $\mathrm{X}$ & $\mathrm{X}$ & $\mathrm{X}$ \\
\hline Totais & 1.132 & 100,0 & 100,0 & 100,0 & 300,0 & - & - & - & - \\
\hline
\end{tabular}


Tabela 2. Dados do "levantamento rápido" no Cerrado sentido restrito na Fazenda Água Limpa, DF, Brasil. Número de espécies (N. espécies) refere-se às espécies inéditas que foram registradas a cada período de cino minutos, indicando quantos metros foram percorridos a cada intervalo. L1+L2+L3 refere-se aos dados obtidos pelas três linhas em conjunto ("metros" - média das três linhas). Para os trechos T1, T2 e T3 (Linha 1) ver Figura 1.

\begin{tabular}{|c|c|c|c|c|c|c|c|c|}
\hline \multirow{2}{*}{$\begin{array}{l}\text { Tempo } \\
\text { (min.) }\end{array}$} & \multicolumn{2}{|c|}{$\mathrm{L} 1$} & \multicolumn{2}{|c|}{ L2 } & \multicolumn{2}{|c|}{ L3 } & \multicolumn{2}{|c|}{$\mathrm{L} 1+\mathrm{L} 2+\mathrm{L} 3$} \\
\hline & Metros & N. espécies & Metros & N. espécies & Metros & N. espécies & "metros" & N. espécies \\
\hline 5 & 43 (T1) & 24 & 55 & 31 & 58 & 35 & 52 & 46 \\
\hline 10 & $53(\mathrm{~T} 1)$ & 14 & 85 & 15 & 81 & 7 & 73 & 10 \\
\hline 15 & $50(\mathrm{~T} 1)$ & 11 & 73 & 9 & 106 & 7 & 76 & 5 \\
\hline 20 & 75 (T2) & 6 & 93 & 1 & 128 & 7 & 99 & 2 \\
\hline 25 & 92 (T2) & 2 & 118 & 1 & 142 & 4 & 117 & 1 \\
\hline 30 & 109 (T3) & 2 & 131 & 1 & 151 & 1 & 130 & 2 \\
\hline 35 & 129 (T3) & 0 & 121 & 1 & 159 & 0 & 136 & 1 \\
\hline 40 & - & - & 155 & 0 & - & - & $\sim 52$ & 0 \\
\hline Total & 551 & 59 & 831 & 59 & 825 & 61 & $\sim 735$ & 67 \\
\hline
\end{tabular}

a menos que o LR (Tab. 4). Comparando somente com L1, as parcelas apresentaram uma espécie, três gêneros e três famílias a menos que o LR.

Em toda aquela porção da FAL, pelos dois métodos foram encontradas 68 espécies, 54 gêneros e 32 famílias (Tab. 1, 4). As famílias mais representativas em termos de espécies, por ambos os métodos, foram Leguminosae (com 12 espécies), Vochysiaceae (seis espécies), Apocynaceae e Malpighiaceae (quatro espécies cada), Erythroxylaceae, Melastomataceae, Myrtaceae e Palmae (com três espécies cada) (Tab. 1).

A curva espécies $\times$ área traçada também sugere estabilização, que se inicia a partir de 0,8 ha, indicando a suficiência da amostragem por parcelas (Fig. 2B).

As principais espécies da presente amostragem por parcelas não diferiram substancialmente dos dados indicados por Felfili \& Silva Júnior (1992), embora as posições de Schefflera macrocarpa ( $5^{\mathrm{a}}$ mais importante no presente e $16^{\mathrm{a}}$ naquele outro), Blepharocalyx salicifolius $\left(10^{\mathrm{a}}\right.$ e $\left.33^{\mathrm{a}}\right)$, Palicourea rigida $\left(29^{\mathrm{a}}\right.$ e $\left.9^{\mathrm{a}}\right)$, Byrsonima coccolobifolia $\left(57^{\mathrm{a}} \mathrm{e}\right.$ $\left.17^{\mathrm{a}}\right)$ e Byrsonima verbascifolia $\left(42^{\mathrm{a}}\right.$ e $\left.13^{\mathrm{a}}\right)$ tenham mudado de maneira substancial. Igualmente, espécies como Annona crassiflora Mart., Andira paniculata Benth., Machaerium opacum Vog., Plenckia populnea, Vatairea macrocarpa (Benth.) Ducke e Tocoyena formosa (Felfili \& Silva Júnior 1992) não ocorreram na porção do Cerrado agora amostrado, embora sejam observadas nas proximidades. Essas espécies, além de Pouteria torta, foram registradas por Ratter (1991), mas não foram encontradas na presente amostragem. Dessa relação, Annona crassiflora, Andira paniculata, Machaerium opacum e Vatairea macrocarpa também não foram registradas nas demais linhas do LR - o que diminui o impacto da necessária falta de aleatorização das parcelas, já comentada nos métodos.

A maior importância de Ouratea hexasperma deveu-se a sua grande densidade naquele trecho (139 ind./ha; $\mathrm{Dr}=13,5 \%$ ), sendo que a segunda posição

A
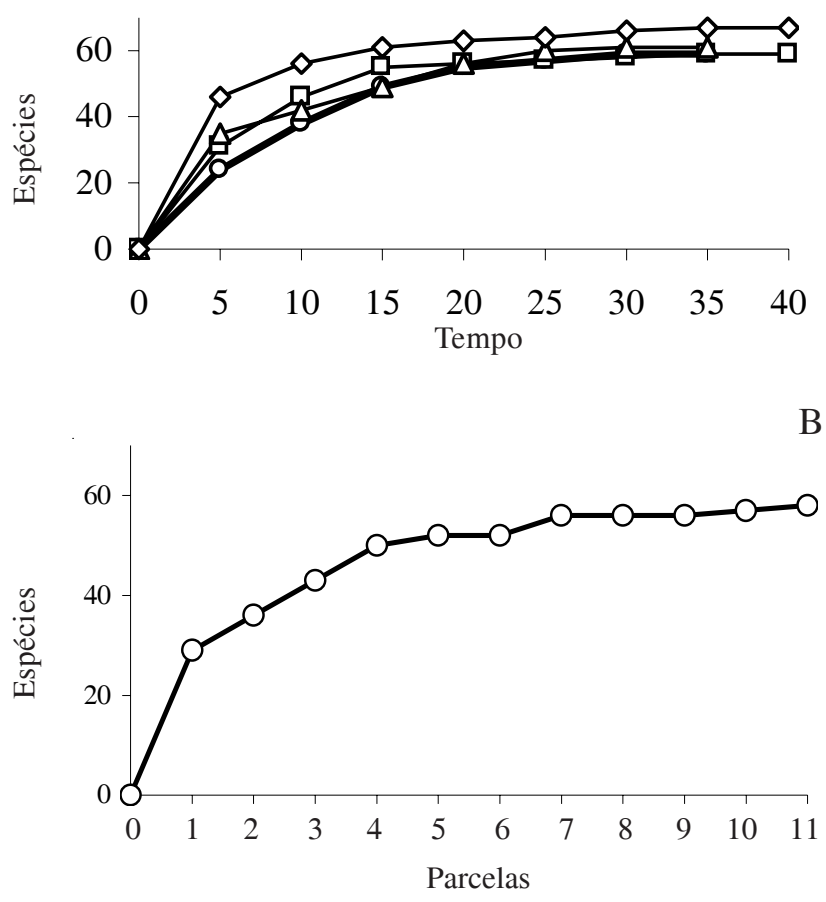

Figura 2. Curvas espécies $\times$ tempo (A) obtidas no "levantamento rápido" (geral = linha $1+$ linha $2+$ linha3) e curva espécies-área (B) obtida pelo método de parcelas no Cerrado sentido restrito da Fazenda Água Limpa, DF, Brasil. (Fig. 1A=-O-= L1; $\square-=$ L2; $-\triangle-=\mathrm{L} 3 ;-\diamond-=$ Geral). 
Tabela 3. Comparação entre o presente estudo e outros levantamentos realizados em trechos de Cerrado sentido restrito na APA do Gama e Cabeça de Veado, DF, Brasil. Siglas do local, ver texto.

\begin{tabular}{|c|c|c|c|c|}
\hline Autor(es) & Local & Método & Área amostral & Espécies \\
\hline Felfili et al. (1992; 1994) & APA & Parcelas $(20 \times 50 \mathrm{~m})$ & 1,0 ha & 66 \\
\hline Sato \& Miranda (1996)* & IBGE & Parcelas $(20 \times 50 \mathrm{~m})$ & 0,5 ha & $57,58,59$ \\
\hline Oliveira \& Gibbs (2000) & JBB & Ponto-quadrante (100) & - & 59 \\
\hline Sambuichi \& Eiten (2000) & JBB & Parcelas $(20 \times 50 \mathrm{~m})$ & 1,0 ha & 92 \\
\hline Ratter (1991) & FAL & Parcelas $(25 \times 10 \mathrm{~m})$ & 0,475 ha & 48 \\
\hline Felfili \& Silva Júnior (1988; 1992) & FAL & Parcelas $(20 \times 50 \mathrm{~m})$ & 2,1 ha & 61 \\
\hline Este estudo (L1, L2, L3) & FAL & Caminhamento & - & 67 \\
\hline Este estudo (apenas L1) & FAL & Caminhamento & - & 59 \\
\hline Este estudo (parcelas) & FAL & Parcelas $(20 \times 50 \mathrm{~m})$ & 1,1 ha & 58 \\
\hline
\end{tabular}

*Dados referentes a três levantamentos, cada um com 0,5 ha de área total amostrada.

de Sclerolobium paniculatum baseou-se na dominância $\left(1,19 \mathrm{~m}^{2} / \mathrm{ha}\right.$, DoR $\left.=15,35 \%\right)$, muito superior às demais espécies (Tab. 1). Os indivíduos mais altos daquela comunidade pertencem a essa espécie, alcançando até $12 \mathrm{~m}$ de altura total (em média 8 a $10 \mathrm{~m}$ ), com diâmetros variando entre 15 e $23 \mathrm{~cm}$. Qualea parviflora, a terceira espécie mais importante, apresentou altos valores de densidade (a segunda maior) e dominância (a terceira maior). Essa espécie, seguida por Ouratea hexasperma, Qualea grandiflora e Sclerolobium paniculatum foram as mais importantes no estudo de Felfili \& Silva Júnior (1992).

Levantamento rápido em $\mathrm{L} 1 \times$ parcelas $-\mathrm{Na}$ comparação dos resultados da fitossociologia com o levantamento rápido em $\mathrm{L} 1$ foi interessante observar que, mesmo que as parcelas tenham englobado completamente os segmentos de L1 (Fig. 1), algumas diferenças florísticas entre os métodos foram reveladas. Espécies não observadas em L1, como Acosmium dasycarpum, Butia archeri, Kielmeyera

Tabela 4. Riqueza florística registrada na amostragem por parcelas, pelo "levantamento rápido" e pelas Linhas do "levantamento rápido" no Cerrado sentido restrito na Fazenda Água Limpa, DF, Brasil.

\begin{tabular}{lccc}
\hline Método & Famílias & Gêneros & Espécies \\
\hline Parcelas & 27 & 45 & 58 \\
Linha 1 (L1) & 30 & 48 & 59 \\
Linha 2 (L2) & 29 & 46 & 59 \\
Linha 3 (L3) & 31 & 47 & 61 \\
"Levantamento rápido" & 32 & 53 & 67 \\
$\quad$ (L1 + L2 + L3) & & & \\
$\quad \begin{array}{l}\text { Total (Parcelas + } \\
\quad \text { "levantamento rápido") }\end{array}$ & 32 & 54 & 68 \\
\hline
\end{tabular}

speciosa e Lafoensia pacari, entraram na amostragem por parcelas. Todas possuíam poucos indivíduos na amostra, estando as duas primeiras presentes com dois indivíduos cada, Kielmeyera speciosa com um e Lafoensia pacari com três (Tab. 1). Com exceção de Acosmium dasycarpum, todos aqueles indivíduos estavam posicionados nos limites das parcelas, portanto na fronteira do campo de visão médio estipulado para o LR. Já os indivíduos de Acosmium dasycarpum encontravam-se praticamente desprovidos de folhas, as quais, além dessa dificuldade, estavam muito atacadas por insetos. Isso explica o fato de seus indivíduos terem passado despercebidos no LR em L1. Posteriormente, no levantamento de L2 e L3, a espécie também não foi registrada, sendo o único táxon incluído exclusivamente pelo método de parcelas (Tab. 1).

Por outro lado, espécies incluídas em L1 como Davilla elliptica, Casearia sylvestris, Bauhinia sp. e Brosimum gaudichaudii não foram incluídas no método de parcelas, por possuírem diâmetros de tronco inferiores ao mínimo estabelecido de $5 \mathrm{~cm}$. Alguns indivíduos de Casearia e Davilla chegaram a apresentar medidas como 4,9 cm de diâmetro, mas, ainda assim, inferiores ao critério mínimo aqui adotado. Isso mostra que o LR não é rígido no critério de inclusão de espécies, confiando apenas na sensibilidade do olho humano, que é falível. Casearia sylvestris e Bauhinia sp. foram novamente observadas em L2 e L3, mas não foram incluídas pois, presumivelmente, seus indivíduos não se encaixariam no critério mínimo de $5 \mathrm{~cm}$. Contudo, Davilla elliptica e Brosimum gaudichaudii foram incluídas (Tab. 1), uma vez que foram encontrados indivíduos que pareceram possuir $\mathrm{DA}_{30}$ grande o suficiente. Diferente de Ratter et al. (2001; 2003), que registraram espécies a partir da observação de indivíduos jovens dos táxons 
pertencentes ao estrato arbóreo, por princípio evitou-se essa inclusão, visando a uma análise ortodoxa dessa característica do método.

Talvez seja interessante que o LR inclua medidas eventuais com algum equipamento leve, como fitas diamétricas, métricas ou mesmo sutas, para dirimir as muitas dúvidas que surgem sobre esse aspecto no campo. Essa checagem de campo não retarda a amostragem, ao mesmo tempo em que dá mais solidez ao critério mínimo de inclusão de espécies - que é um aspecto sujeito à crítica.

Na L1, um caso interessante de não inclusão na amostragem por parcelas foi Symplocos rhamnifolia, que foi relacionada no primeiro trecho (T1) durante o LR. Embora não haja dúvida de que a espécie ocorre na FAL (Felfili \& Silva Júnior 1992; Ratter 1991), tendo sido novamente relacionada nas linhas L2 e L3 (Tab. 1), durante a amostragem por parcelas ela não foi mais observada. Duas possibilidades foram levantadas para explicar sua ausência: ou ela passou despercebida na amostragem por parcelas pelo fato do único indivíduo observado no LR não ter atendido ao critério mínimo de inclusão (enquanto os indivíduos de Symplocos registrados em L2 e L3 facilmente passariam por este critério); ou ela foi mal identificada durante o LR. Os indícios mais fortes recaíram sobre essa segunda hipótese, parecendo que algum indivíduo de outra espécie tenha sido erroneamente identificado.

Essa discussão remete ao fato de que o LR não poderá ser criteriosamente aplicado por iniciantes nos estudos de vegetação e na identificação de campo das plantas que se pretenda amostrar, uma limitação já destacada por Ratter et al. (2000; 2001). Esse método requisita técnicos com ampla experiência e um sólido conhecimento da flora em questão, que reconheçam no campo mudanças devidas às diferentes fenofases, com ou sem material reprodutivo, para que o método possa ser aplicado com segurança. Filgueiras et al. (1994) consideraram a exigência de um profissional com profundo conhecimento da flora local como a principal desvantagem do método de "caminhamento". Mesmo que os trabalhos fitossociológicos pelos métodos usuais de amostragem, por parcelas ou distâncias, também requisitem bons técnicos na identificação de campo, essa exigência pode ser parcialmente contornada pela marcação de indivíduos e pela coleta sistemática do material botânico que vai sendo encontrado nas unidades amostrais. Como tempo e custos não são variáveis fundamentais neste caso, equipes maiores podem ser formadas, e algum participante pode dedicar-se exclusivamente às coletas para herbário. No LR tempo é fundamental, de modo que as coletas podem ser feitas, mas não de forma sistemática nem para os elementos comuns da vegetação. Os métodos rápidos devem ser simples, baratos e executados por equipes pequenas e pessoal experiente (Fonseca 2001).

Parcelas $\times$ tempo - Foram necessárias mais de sete horas e 40 minutos para amostrar-se o hectare preconizado por Felfili et al. (2001); ou mais de oito horas e 17 minutos para obter-se os dados utilizados na confecção da Tab. 1. Se considerado o critério "homem/hora", neste caso, teriam sido necessárias mais de 15 horas e 20 minutos, ou 16 horas e 30 minutos, respectivamente, uma vez que, diferente do LR que pode ser feito por uma só pessoa, para parcelas são necessárias duas pessoas no mínimo.

Cada parcela levou em média 10 minutos para ser instalada no campo e 35 minutos para ser amostrada (45 minutos gastos em média no total, por parcela). Somente para alocar 10 parcelas foi necessário um tempo três vezes maior (103 minutos) do que todo o LR de L1 (35 minutos). Enquanto para este foram percorridos $551 \mathrm{~m}$, para as parcelas percorreu-se um trecho de, no mínimo, $1.400 \mathrm{~m}$ somente para alocar as 10 parcelas $(50 \times 20 \mathrm{~m} \times 2 \times 10$ parcelas $)$, excetuando-se o muito que se percorre entre parcelas e dentro de cada parcela.

O tempo gasto para amostragem das parcelas foi positivamente correlacionado com o número total de árvores presentes nestas $\left(\mathrm{r}_{s}=0,781 ; \mathrm{n}=11 ; \mathrm{p}=0,004\right)$. $\mathrm{Na}$ área de estudo, em média foram gastos de 17 a 28 segundos para obter as medidas de diâmetro e altura de cada indivíduo. A tomada do diâmetro de um indivíduo isolado levava em torno de sete segundos para ser feita, enquanto um único indivíduo bifurcado, de caule não cilíndrico, ou de caules múltiplos, como Syagrus flexuosa, pode levar em torno de 30 segundos ou mais para ser concluída. A tomada de dados de altura foi mais lenta que a medição dos diâmetros (de 10 a 15 segundos).

Para aplicar o método de parcelas, geralmente equipes treinadas com três a quatro participantes levam de três a cinco dias para amostrar um hectare de Cerrado, alocando-se cada uma das 10 parcelas de maneira aleatória e distante uma das outras. No presente estudo não foi considerado o tempo necessário para concluir uma parcela em um local, recolher o material, seguir para um local novo e distante para instalar outra parcela.

Adaptações e comentários sobre os métodos - No 
presente estudo alguns procedimentos metodológicos do LR foram aplicados com modificações em relação ao que é preconizado por Ratter et al. (2000; 2001; 2003), mas que não alteraram o objetivo pretendido e permitiram a comparação dos métodos. O primeiro deles refere-se ao fato da L1 ter sido segmentada em três partes, cada qual uma reta praticamente perfeita (Fig. 1). Na prática, o que se faz é uma caminhada única numa direção, que busca ser retilínea, mas que jamais será perfeita. O procedimento normal (uma linha "imperfeita") só foi adotado nas linhas L2 e L3.

A segunda modificação refere-se à recomendação da participação de três integrantes (Ratter et al. 2001), distanciados $20 \mathrm{~m}$ entre si, realizando o levantamento concomitantemente. Como somente os autores fizeram as amostragens do presente estudo, medindo o quanto se caminhava em cada linha a cada intervalo de cinco minutos, optou-se por distanciar as linhas de caminhada em $500 \mathrm{~m}$ para incluir porções menos homogêneas da vegetação. Esse procedimento revelou que trechos em mosaico estrutural tendem a ampliar o intervalo de caminhada (L2 e L3), comparado a um trecho estruturalmente homogêneo (L1), e certamente favorecem a entrada de espécies inéditas.

Quanto ao tempo, custos e pessoal deve ser considerado que uma linha de LR pode ser amostrada por um único técnico experiente, o qual pode executar vários levantamentos ao longo de um dia. Mas, o ideal parece ser com dois integrantes: um observando a vegetação e outro anotando os nomes e auxiliando-o naquela tarefa (procedimento aqui adotado). Isto torna o método muito robusto quanto à quantidade de informação florística obtida, com custos baixos. Se a equipe for maior, vários levantamentos ou caminhadas podem ser realizados simultaneamente. Enquanto o LR pode ser aplicado por uma única pessoa, para amostrar-se parcelas são necessárias, no mínimo, duas pessoas - e até cinco segundo Felfili et al. (2001).

Medidas de abundância pelo LR e outras considerações - No presente estudo, a indicação da frequiência de ocorrência das espécies observadas foi feita de modo mais informal do que o recomendado (Filgueiras et al. 1994; Ratter et al. 2001), pois como já se conhecia o Cerrado da FAL poder-se-ia ser tendencioso. Manteve-se apenas o registro das plantas que pareceram mais abundantes naquele trecho, sem preocupação com as menos abundantes. Ao fazer isso constatou-se, após o resultado da fitossociologia, que se a informação de abundância for tomada, ela deverá ser avaliada com extrema cautela - ou, até mesmo, é melhor que seja evitada em caso de dúvidas. Plantas que atingem dimensões maiores, como Dalbergia miscolobium, Sclerolobium paniculatum e Vochysia thyrsoidea, ou as que estejam floridas, por serem vistosas, acabam por ser consideradas freqüientes muito mais pela facilidade com que são observadas do que por sua efetiva abundância. J.A. Ratter (com. pes.) sugere que mais do que um valor de abundância, essa indicação de freqüência tende a registrar valores de cobertura, destacando as plantas com maior área basal.

Logo, uma noção precisa sobre a frequiência das espécies nas comunidades levantadas somente poderá ser obtida com base em algum método quantitativo - e o método de parcelas aqui estudado, mais uma vez, mostrou-se adequado (Felfili et al. 1992; 1994; 2001; Felfili \& Silva Júnior 1993; 2001). Porém, se o interesse for apenas qualitativo, de presença ou ausência das espécies, o LR pode ser uma opção interessante.

O LR é antes florístico do que vegetacional. Por seu lado, parcelas e outros métodos quantitativos são ferramentas para trabalhos vegetacionais, mas que também agregam sólidas informações florísticas. Sendo assim, o LR possui grande potencial na obtenção de informação florística rápida e de qualidade sobre a vegetação arbórea do Cerrado sentido restrito, sendo um método que deve ser considerado como importante ferramenta auxiliar no conhecimento da flora e para a conservação ambiental.

\section{Agradecimentos}

Agradecemos aos colegas José Felipe Ribeiro, José Roberto Moreira e James Alexander Ratter, pelas relevantes sugestões; ao Dr. Fábio Rubio Scarano e aos revisores anônimos por terem tornado o texto mais leve e por nos confrontarem com bons argumentos.

\section{Referências bibliográficas}

Alder, D. \& Synnott, T.J. 1992. Permanent sample plot techniques for mixed tropical forest. Tropical Forestry Papers, 25. Oxford, Oxford Forestry Institute, Department of Plant Sciences.

Anderson W.R. 1996. The importance of duplicate specimens in Herbaria. Pp. 239-248. In: T.F. Stuessy \& S.H. Sohmer (eds.). Sampling the green world. New York, Columbia University Press.

Alverson, W.S.; Moskovits, D.K. \& Shopland, J.M. (eds.) 2000. Bolívia, Pando, Rio Tahuamanu: rapid biological inventories, Report 1. Chicago, Illinois, The Field Museum.

Brower, J.E.; Zar, J.H. \& Von Ende, C.N. 1990. Field and laboratory methods for general ecology. $3^{\text {rd }}$ ed. United States, Wm. C. Brown Publishers. 
Brummitt, R.K. \& Powell, C.E. 1992. Authors of plant names. Kew, Royal Botanic Gardens.

Cain, S.A. \& Castro, G.M.O. 1971. Manual of vegetation analysis. Facsimile of the 1959 edition. New York, Hafner Publishing Company.

Cochrane, T.T.; Sánchez, L.G.; Azevedo, L.G.; Porras, J.A. \& Garver, C.L. 1985. Land in tropical America = La tierra en la América Tropical = A terra na América Tropical. Planaltina, Centro Internacional de Agricultura Tropical (CIAT), Cali, Empresa Brasileira de Pesquisa Agropecuária, EMBRAPA Cerrados, 3 vols.

Cottam, G. \& Curtis, J.T. 1956. The use of distance measures in phytosociological sampling. Ecology 37(13): 451-460.

Dias, A.C.; Negreiros, O.C.; Veiga, A.A. \& Couto, H.T.Z. 1989. Comparação entre métodos empregados na amostragem de vegetação, desenvolvida em comunidade de Floresta Pluvial Tropical. Revista do Instituto Florestal 1(2): 93-119.

Droege, S.; Cyr, A. \& Larivée, J. 1998. Checklists: an underused tool for the inventory and monitoring of plants and animals. Conservation biology 12(5): 1134-1138.

Emmons, L.H. 1997. Neotropical Rainforest Mammals: a field guide. $2^{\text {nd }}$ ed. Chicago, University of Chicago Press.

Felfili, J.M. \& Silva Júnior, M.C. 1988. Distribuição dos diâmetros numa faixa de cerrado na Fazenda Água Limpa (FAL) Brasília-DF. Acta Botanica Brasilica 2(1-2): 85-105.

Felfili, J.M. \& Silva Júnior, M.C. 1992. Floristic composition, phytosociology and comparison of cerrado and gallery forests at Fazenda Água Limpa, Federal District, Brazil. Pp. 395-416. In: P.A. Furley; J.A. Proctor \& J.A. Ratter (eds.). Nature and dynamics of forest-savanna boundaries. London, Chapman \& Hall.

Felfili, J.M. \& Silva Júnior, M.C. 1993. A comparative study of cerrado (sensu stricto) vegetation in Central Brazil. Journal of Tropical Ecology 9: 277-289.

Felfili, J.M. \& Silva Júnior, M.C. (orgs.). 2001. Biogeografia do bioma Cerrado: estudo fitofisionômico na Chapada do Espigão Mestre do São Francisco. Brasília, Universidade de Brasília.

Felfili, J.M.; Silva Júnior, M.C.; Rezende, A.V.; Machado, J.W.B.; Walter, B.M.T.; Silva, P.E.N. \& Hay, J.D. 1992. Análise comparativa da florística e fitossociologia da vegetação arbórea do Cerrado sensu stricto na Chapada Pratinha, Brasil. Acta Botanica Brasilica 6(2): 27-46.

Felfili, J.M.; Filgueiras, T.; Haridasan, M.; Silva Júnior, M.C.; Mendonça, R.C. \& Rezende, A.V. 1994. Projeto Biogeografia do Bioma Cerrado: vegetação e solos. Cadernos de Geociências 12: 75-166.

Felfili, J.M.; Silva Júnior, M.C.; Rezende, A.V.; Haridasan, M.; Filgueiras, T.S.; Mendonça, R.C.; Walter, B.M.T. \& Nogueira, P.E. 2001. O projeto Biogeografia do Bioma Cerrado: hipóteses e padronização da metodologia. Pp. 157-173. In: I. Garay \& B. Dias. Conservação da biodiversidade em ecossistemas tropicais: avanços conceituais e revisão de metodologias de avaliação e monitoramento. Petrópolis, Editora Vozes.

Felfili, J.M.; Silva Júnior, M.C.; Sevilha, A.C.; Fagg, C.W.; Walter, B.M.T.; Nogueira, P.E. \& Rezende, A.V. 2004. Diversity, floristic and structural patterns of cerrado vegetation in central Brazil. Plant Ecology 175: 37-46.
Filgueiras, T.S.; Nogueira, P.E.; Brochado, A.L. \& Guala II, G.F. 1994. Caminhamento: um método expedito para levantamentos florísticos qualitativos. Cadernos de Geociências 12: 39-43.

Fonseca, G.A.B. Proposta para um programa de avaliação rápida em âmbito nacional. 2001. Pp. 150-156. In: I. Garay \& B. Dias. Conservação da biodiversidade em ecossistemas tropicais: avanços conceituais e revisão de metodologias de avaliação e monitoramento. Petrópolis, Editora Vozes.

Foster, R.; Roja, J.G.; Paniagua, N.Z.; Alverson, W.S. \& Torrico, G.P. 2000. Flora and vegetation. Pp.29-34. In.: W.S. Alverson; D.K. Moskovits \& J.M. Shopland (eds.). Bolívia, Pando, Rio Tahuamanu: rapid biological inventories, Report 1. Chicago, Illinois, The Field Museum.

Gibbs, P.E.; Leitão Filho, H.F. \& Abbot, R.J. 1980. Aplication of the point-centred quarter method in a floristic survey of an area of gallery forest at Moji-Guaçu, SP, Brazil. Revista Brasileira de Botânica 3(1/2): 12-22.

Goodland, R.A. \& Ferri, M.G. 1979. Ecologia do Cerrado. Coleção Reconquista do Brasil, 52. Belo Horizonte, Itatiaia.

Heyer, W.R.; Donnely, M.A.; McDiarmind R.W.; Hayek, L.C. \& Foster, M.S. (eds.). 1994. Measuring and monitoring biological diversity: standard methods for amphibians. Washington, Smithsonian Institution.

Klink, C.A. \& Machado, R.B. 2005. Conservation of the brazilian Cerrado. Conservation Biology 19(3): 707-713.

Klink, C.A.; Moreira, A.G. \& Solbrig, O.T. 1993. Ecological impact of agricultural development in the cerrados. Pp. 259-282. In: M.D. Young \& O.T. Solbrig (eds.). The world's savannas: economic driving forces, ecological constraints and policy options for sustainable land use. Unesco, Paris, The Parthenon Publishing Group (Man and Biosphere Series, v.12).

Korning, J.; Thomsen, K. \& Øllgaard, B. 1991. Composition and structure of a species rich Amazonian rain forest obtained by two different sample methods. Nordic Journal of Botany 11(1): 103-110.

Martins, F.R. 1991. Estrutura de uma floresta mesófila. Campinas, Editora da UNICAMP.

Matteucci, S.D. \& Colma, A. 1982. Metodologia para el estudio de la vegetation. Washington, Secretaria General de la Organizacion de los Estados Americanos, Programa Regional de Desarrollo Cientifico y Tecnologico.

Mittermeier, R.A.; Myers, N. \& Mittermeier, C.G. 1999. Hotspots: earth's biologically richest and most endangered terrestrial ecorregions. Mexico City, Cemex, Conservation International.

MMA 1999. Ações prioritárias para a conservação da biodiversidade do Cerrado e Pantanal. Brasília, Conservation International do Brasil / FUNATURA / UnB / Fundação Biodiversitas / MMA.

Müeller-Dombois, D. \& Ellenberg, H. (eds.). 1974. Aims and methods of vegetation ecology. New York, John Wiley.

Myers, N.; Mittermeier, R.A.; Mittermeier, C.G.; Fonseca, G.A.B. \& Kent, J. 2000. Biodiversity hotspots for conservation priorities. Nature 403: 853-858. 
Oliveira, A.A. 2000. Inventários quantitativos de árvores em Matas de Terra Firme: histórico com enfoque na Amazônia brasileira. Acta Amazonica 30(4): 543-567.

Oliveira, P.E. \& Gibbs, P.E. 2000. Reproductive biology of woody plants in a cerrado community of Central Brazil. Flora 195: 311-329.

Oliveira, P.S. \& Marquis, R.J. 2002. The Cerrados of Brazil: ecology and natural history of a neotropical savanna. New York, Columbia University Press.

Pinto, M.N. (coord.). 1990. Cerrado: caracterização, ocupação e perspectivas. Brasília, Editora da Universidade de Brasília/Sematec.

Ratter, J.A. 1980. Notes on the vegetation of Fazenda Água Limpa (Brasília, DF, Brazil). Edinburgh, Royal Botanic Garden Edinburgh.

Ratter, J.A. 1991. Guia para a vegetação da Fazenda Água Limpa (Brasília, DF): com uma chave para os gêneros lenhosos de dicotiledôneas do cerrado. Brasília, Editora da Universidade de Brasília.

Ratter, J.A.; Bridgewater, S.; Atkinson, R. \& Ribeiro, J.F. 1996. Analysis of floristic composition of the brazilian cerrado vegetation II: comparison of the woody vegetation of 98 area. Edinburgh Journal of Botany 53(2): 153-180.

Ratter, J.A.; Ribeiro, J.F. \& Bridgewater, S. 1997. The brazilian cerrado vegetation and threats to its biodiversity. Annals of Botany 80: 223-230.

Ratter, J.A.; Bridgewater, S.; Ribeiro, J.F.; Dias, T.A.B. \& Silva, M.R. 2000. Estudo preliminar da distribuição das espécies lenhosas da fitofisionomia cerrado sentido restrito nos estados compreendidos pelo bioma Cerrado. Boletim do Herbário Ezechias Paulo Heringer 5: 5-43.

Ratter, J.A.; Bridgewater, S. \& Ribeiro, J.F. 2001. Espécies lenhosas da fitofisionomia cerrado sentido amplo em 170 localidades do bioma Cerrado. Boletim do Herbário Ezechias Paulo Heringer 7: 5-112.
Ratter, J.A.; Bridgewater, S. \& Ribeiro, J.F. 2002. Biodiversity patterns of woody cerrado vegetation: an overall view. Pp. 55-57. In: E.L. Araújo; A.N. Moura; E.V.S.B. Sampaio; L.M.S. Gestinari \& J.M.T. Carneiro (eds.). Biodiversidade, conservação e uso da flora do Brasil. Recife, Universidade Federal Rural de Pernambuco, Sociedade Botânica do Brasil.

Ratter, J.A.; Bridgewater, S. \& Ribeiro, J.F. 2003. Analysis of floristic composition of the Brazilian cerrado vegetation III: comparison of the woody vegetation of 376 areas. Edinburgh Journal of Botany 60(1): 57-109.

Reis, I.A. \& Assunção, R.M. 1998. Comparando três métodos de amostragem: métodos de distâncias, contagem de quadrats e conglomerado adaptativo. Scientia Forestalis 54: 119-130.

Ribeiro, J.F. \& Walter, B.M.T. 1998. Fitofisionomias do bioma Cerrado. Pp. 87-166. In: S.M. Sano \& S.P. Almeida (eds.). Cerrado: ambiente e flora. Planaltina, Embrapa Cerrados.

Ribeiro, J.F.; Fonseca, C.E.L. \& Sousa-Silva, J.C. 2001. Cerrado: caracterização e recuperação de Matas de Galeria. Planaltina, Embrapa Cerrados.

Sambuichi, R.H.R. \& Eiten, G. 2000. Fitossociologia da camada lenhosa de um cerrado em Brasília, DF. Boletim do Herbário Ezechias Paulo Heringer 5: 62-87.

Sano, S.M. \& Almeida, S.P. (eds.). 1998. Cerrado: ambiente e flora. Brasília, Embrapa Cerrados.

Sato, M.N. \& Miranda, H.S. 1996. Mortalidade de plantas lenhosas do cerrado sensu stricto submetidas a diferentes regimes de queima. Pp. 102-111. In: H.S. Miranda; C.H. Saito \& B.F.S. Dias (orgs.). Impactos de queimadas em áreas de cerrado e restinga. Brasília, Universidade de Brasília.

Wilson, D.E.; Cole, F.R.; Nichols, J.D.; Rudran, R. \& Foster, M.S. (eds.). 1996. Measuring and monitoring biological diversity: standard methods for mammals. Washington, Smithsonian Institution.

Zar, J.H. 1999. Biostatistical analysis. $4^{\text {th }}$ ed. New Jersey, Prentice Hall. 